\title{
Dual Roles for Calcium Ions in Apical Growth of Neurospora crassa
}

\author{
By JAN SCHMID ${ }^{1 * \dagger}$ AND FRANKLIN M. HAROLD ${ }^{1,2}$ \\ ${ }^{1}$ Department of Molecular and Cellular Biology, National Jewish Center for Immunology and \\ Respiratory Medicine, Denver, Colorado 80206, USA \\ ${ }^{2}$ Department of Biochemistry, Biophysics and Genetics, University of Colorado Health Sciences \\ Center, Denver, Colorado 80262, USA
}

(Received 19 January 1988; revised 30 May 1988)

\begin{abstract}
We report initial attempts to define the role of $\mathrm{Ca}^{2+}$ in the polarized extension of Neurospora crassa. Growth of the organism was diminished in media containing less than $1 \mathrm{~mm}-\mathrm{Ca}^{2+}$; extension was more severely impaired than biomass synthesis, resulting in the formation of stubby, bulbous hyphae, even of spherical cells. Reduced extension and abnormal morphology were correlated with the loss of surface-bound $\mathrm{Ca}^{2+}$, probably associated with the cell wall. Intracellular $\mathrm{Ca}^{2+}$ may be represented by material that fluoresces brightly in the presence of chlortetracycline. Punctate fluorescent bodies and diffuse fluorescence were both arrayed in a longitudinal gradient, maximum apically. Addition of the calcium ionophore A23187 induced dissipation of the fluorescence; concurrently, the hyphae lost as much as one half of their $\mathrm{Ca}^{2+}$ content. Extension continued almost unabated, but multiple branches quickly emerged from the apex. The observations suggest that a cytoplasmic $\mathrm{Ca}^{2+}$ gradient is not required for polarized extension, but may play a role in ensuring the dominance of the apex.
\end{abstract}

\section{INTRODUCTION}

Our present understanding of the role of $\mathrm{Ca}^{2+}$ in the polarization of tip-growing cells rests primarily on evidence from plants and algae (reviews: Hepler \& Wayne, 1985; Schnepf, 1986; Krauss, 1987). Key findings include the uptake of $\mathrm{Ca}^{2+}$ into the apex of pollen tubes and fucoid rhizoids (Jaffe et al., 1975a, b; Robinson \& Jaffe, 1975); the dependence of extension on $\mathrm{Ca}^{2+}$ and its inhibition by reagents thought to block $\mathrm{Ca}^{2+}$ uptake (Picton \& Steer, 1983, 1985; Reiss \& Herth, 1985; Kropf \& Quatrano, 1987); and the demonstration of cytoplasmic $\mathrm{Ca}^{2+}$ gradients, maximum apically (Jaffe et al., 1975b; Reiss \& Herth, 1978, 1979; Reiss et al., 1985; Brownlee \& Wood, 1986: Kropf \& Quatrano, 1987; Nobiling \& Reiss, 1987). $\mathrm{Ca}^{2+}$ ions are thought to play a central role in regulating apical extension. For example, Picton \& Steer (1982) proposed that $\mathrm{Ca}^{2+}$ ions flow into the apex; the locally elevated level of cytosolic $\mathrm{Ca}^{2+}$ confines the exocytosis of precursor vesicles to the apical cap. Immediately behind the apex, $\mathrm{Ca}^{2+}$ is sequestered in storage vesicles. The reduced level of post-apical free $\mathrm{Ca}^{2+}$ would elicit relaxation of the microfilament meshwork that subtends and supports the tip, allowing the apex to extend. The evidence presently available is broadly consistent with this hypothesis.

Regarding the fungi, information is both sparse and scattered. $\mathrm{Ca}^{2+}$ ions appear to be generally required for growth and sporulation (Silver, 1977; Pitt \& Ugalde, 1984; Ohya et al., 1986), but their function is unclear. There is evidence that $\mathrm{Ca}^{2+}$ ions help maintain the ionic permeability of the plasma membrane (Slayman, 1965; Van Brunt et al., 1982) and stabilize cell walls (Dow \& Rubery, 1975). A role in the regulation of apical extension is suggested by the

† Present address: Department of Biology, University of Iowa, Iowa City, IA 52242, USA.

Abbreviations: CTC, chlortetracycline; FRIPI, Fries-PIPES medium; NPN, $N$-phenyl-1-naphthylamine. 
observation that calcium ionophores induce branching in Neurospora and Achlya (Reissig \& Kinney, 1983; Harold \& Harold, 1986); and also by the gradient of intracellular $\mathrm{Ca}^{2+}$ that Reiss \& Herth (1979) noted in Achlya. Calcium channels have been documented only in Blastocladiella (Caldwell et al., 1986). The experiments described here suggest that $\mathrm{Ca}^{2+}$ ions exert dual effects, in the cytoplasm and in the cell wall.

\section{METHODS}

Organisms and growth media. Neurospora crassa RL21A was maintained on Vogel's medium as described by Davis \& de Serres (1970). Mass cultures were grown on FRIPI medium, a modified Fries' medium (Davis \& de Serres, 1970) containing $160 \mu \mathrm{M}$-EGTA and $500 \mathrm{~mm}$-PIPES, adjusted to $\mathrm{pH} 7.0$ with $\mathrm{NaOH}$. The basal $\mathrm{Ca}^{2+}$ level of this medium, prior to the addition of $\mathrm{Ca}^{2+}$, was $38.6 \mu \mathrm{M} ; 36 \mu \mathrm{M}-\mathrm{Ca}^{2+}$ was derived from the Fries' medium salts (determined by use of an Orion calcium electrode) and $2.6 \mu \mathrm{M}-\mathrm{Ca}^{2+}$ was contributed by the PIPES (information supplied by the manufacturers). The $\mathrm{Ca}^{2+}$ concentration was adjusted by adding $\mathrm{CaCl}_{2}$; free $\mathrm{Ca}^{2+}$ concentrations were calculated, with due attention to $\mathrm{pH}$ and $\mathrm{Mg}^{2+}$, by use of the dissociation constants published by Caldwell (1970) and a BASIC program (J. Schmid, W. J. A. Schreurs \& D. Krauss-Varban, unpublished).

Calcium dependence of growth. FRIPI medium $(500 \mathrm{ml})$ was inoculated with $5 \times 10^{5}$ conidia $\mathrm{ml}^{-1}$, and incubated at $25^{\circ} \mathrm{C}$ with rotation at 200 r.p.m. Rates of biomass increase and extension were monitored during the exponential phase of growth, 14-27 h after inoculation. Biomass was measured as the dry weight of mycelium harvested from samples by filtration through Nuclepore filters (pore size, $3 \mu \mathrm{m}$ ); filters were washed with distilled water. Extension was monitored by the contour length of the hyphae at a magnification of 200-400 $\times$; 36 hyphae were averaged for each time point. Ten samples were collected during the exponential phase for measurements of biomass and of extension; the results were plotted and the rates of increase were determined from the slope of each line. In some experiments, macromolecule synthesis was also measured: protein was assayed according to Bradford (1976), following extraction for $5 \mathrm{~min}$ with $2 \mathrm{M}-\mathrm{NaOH}$ at $95^{\circ} \mathrm{C}$, RNA by the orcinol method (Dawson $e t$ al., 1986), and DNA according to Labarca \& Paigen (1980).

Extension of individual hyphae was monitored in growth chambers under a Zeiss IM-35 microscope. Hyphae were grown on FRIPI medium without EGTA. Small agar plugs were inverted in a drop of FRIPI medium containing $100 \mu \mathrm{M}-\mathrm{Ca}^{2+}$, placed on the bottom of the chamber. The chamber was then continuously flushed with FRIPI $+100 \mu \mathrm{M}-\mathrm{Ca}^{2+}$ at $0.4 \mathrm{ml} \mathrm{min}{ }^{-1}$. When a hypha emerged from under the plug, its extension was monitored for at least $60 \mathrm{~min}$. The medium was then exchanged for FRIPI $+0.12 \mu \mathrm{M}-\mathrm{Ca}^{2+}$, and extension was observed for another $60 \mathrm{~min}$.

Effects of the calcium ionophore A23187. Individual hyphae were monitored as above, except that the organisms were grown on Fries' medium $\left(900 \mu \mathrm{M}-\mathrm{Ca}^{2+}\right)$. Chambers were flushed with Fries' medium supplemented with $0.2 \%$ dimethyl sulphoxide, with or without $100 \mu \mathrm{M}-\mathrm{A} 23187$.

Fluorescence microscopy. Hyphae were grown on Fries' agar plates and introduced into growth chambers as described above. The medium in these experiments was Fries' supplemented with $100 \mu \mathrm{M}$-chlortetracycline (CTC) or $20 \mu \mathrm{M}-N$-phenyl-1-naphthylamine (NPN) in $0 \cdot 1 \%$ dimethyl sulphoxide. CTC fluorescence was observed under a Zeiss IM-35 microscope by use of a BP400-440 nm excitation filter, an FT460 nm beam splitter and an LP470 nm emission filter. NPN fluorescence was observed with the same emission filter, a $380 / 9 \mathrm{~nm}$ excitation filter and a $405 \mathrm{~nm}$ beam splitter (the latter two from Omega Optical, the others from Zeiss). The light source was a HBO $50 \mathrm{~W}$ super-pressure mercury lamp (Osram). Photographs were taken with Kodak Trix pan film, sensitivity enhanced to 1600 ASA by the use of Acufine developer.

Calcium content. Fries' medium or FRIPI medium of known $\mathrm{Ca}^{2+}$ concentration, supplemented with ${ }^{45} \mathrm{Ca}^{2+}(70-$ $900 \mathrm{kBq} \mathrm{ml}^{-1}$ ) was inoculated with $3-5 \times 10^{6}$ conidia $\mathrm{ml}^{-1}$ and the cultures were grown on a rotary shaker as described above. Duplicate samples $(0 \cdot 1 \mathrm{ml})$ were collected on Millipore filters ( $3 \mu$ pore size) and washed twice with $5 \mathrm{ml}$ cold buffer (hyphae grown on Fries' medium were washed with $10 \mathrm{mM}$-MES/Tris, pH 6; hyphae grown on FRIPI were washed with $10 \mathrm{mM}-\mathrm{PIPES} / 500 \mathrm{mM}-\mathrm{NaCl}$, pH 7). One set of samples was washed with $\mathrm{Ca}^{2+-f r e e}$ buffer, as a measure of total cell-associated ${ }^{45} \mathrm{Ca}^{2+}$. The other was washed with buffer supplemented with $5 \mathrm{mM}$ $\mathrm{CaCl}_{2}$, as a measure of 'intracellular' ${ }^{45} \mathrm{Ca}^{2+}$, i.e. that portion not readily exchangeable. The difference (after correction for radioactivity bound to the filters) was taken to represent ${ }^{45} \mathrm{Ca}^{2+}$ associated with the surface.

Reagents. Chlortetracycline (trade name, aureomycin) was purchased from Serva Chemicals, NPN from Eastman Kodak. A23187 and buffers were purchased from Sigma.

\section{RESULTS}

\section{Extension of $\mathrm{N}$. crassa hyphae requires $\mathrm{Ca}^{2+}$}

Growth of $N$. crassa hyphae was strongly dependent upon the concentration of free $\mathrm{Ca}^{2+}$ in the medium; maximal biomass production required approximately $1 \mathrm{mM}^{-\mathrm{Ca}^{2+}}$ (Fig. 1). Given the 


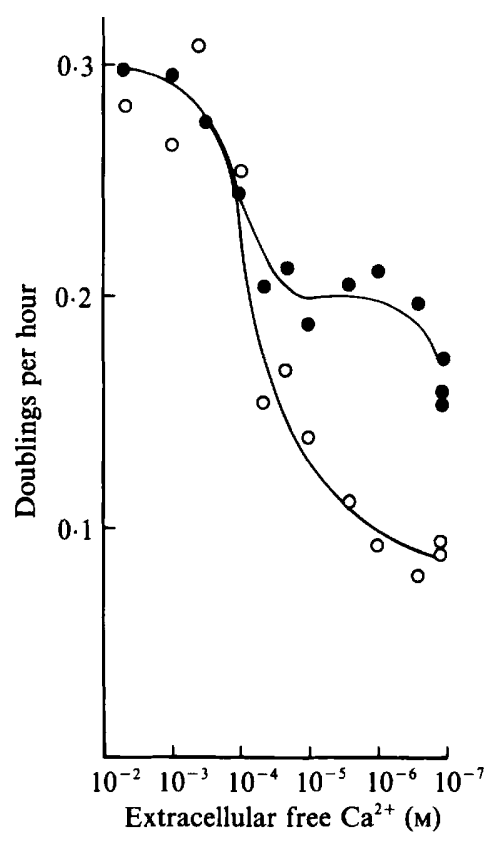

Fig. 1. Effect of extracellular $\mathrm{Ca}^{2+}$ concentration on growth of $N$. crassa. Conidia were inoculated into FRIPI medium containing various concentrations of $\mathrm{Ca}^{2+}$; rates of biomass production $(O)$ and extension $(O)$ were determined during the exponential phase of growth. This is one of three experiments that gave essentially identical results.

multiple and well-established roles of $\mathrm{Ca}^{2+}$ in physiological regulation, this result was not unexpected. But we find it noteworthy that $\mathrm{Ca}^{2+}$ limitation had more drastic effects on the rate of hyphal elongation than on the rate of biomass increase (Fig. 1). The involvement of $\mathrm{Ca}^{2+}$ in extension was also apparent from the morphology of the hyphae (Fig. 2). With decrease in the extracellular $\mathrm{Ca}^{2+}$ concentration, the hyphae became wider as well as shorter, ultimately producing stubby bulbous rods. At $0 \cdot 1 \mu \mathrm{M}-\mathrm{Ca}^{2+}$, approximately $20 \%$ of the population lost the capacity for polarized growth, producing spherical cells up to $20 \mu \mathrm{m}$ in diameter. Organisms growing at the extremes of the range, $5 \mathrm{mM}$ - and $0 \cdot 1 \mu \mathrm{M}-\mathrm{Ca}^{2+}$, were in a state of balanced growth, as judged by the coordinated increase of protein, RNA and DNA with dry weight. Extension of $N$. crassa hyphae required the continuous presence of external $\mathrm{Ca}^{2+}$. When individual hyphae were monitored for the effects of $\mathrm{Ca}^{2+}$ deprivation, extension was inhibited by at least $80 \%$ within $5 \mathrm{~min}$ (data not shown). Under the conditions used to examine individual hyphae, growth frequently ceased altogether, whereas elongation of hyphae in mass cultures merely slowed; we did not pursue the reason for this difference.

In an effort to determine whether $\mathrm{Ca}^{2+}$ ions exert their effects on the external surface or in the cytoplasm, we measured the amounts of total and surface-bound ${ }^{45} \mathrm{Ca}^{2+}$ in hyphae grown at various concentrations of ${ }^{45} \mathrm{Ca}^{2+}$. Fig. 3 shows that the steep decline in the rate of extension below $1 \mathrm{~mm}-\mathrm{Ca}^{2+}$ corresponded to a sharp drop in surface-bound $\mathrm{Ca}^{2+}$. The amount of intracellular $\mathrm{Ca}^{2+}$, like the production of biomass, was less drastically diminished by lowering of the extracellular $\mathrm{Ca}^{2+}$ concentration.

We are aware that the FRIPI medium used in the above experiment is far from optimal. The heavy buffering and use of $\mathrm{pH} 7$ were unavoidable if the free $\mathrm{Ca}^{2+}$ concentration was to be controlled over a wide range, for EGTA is rather ineffective below pH 6.8 and the free $\mathrm{Ca}^{2+}$ concentration becomes extremely sensitive even to minute changes in $\mathrm{pH}$ (Caldwell, 1970). Extension of $N$. crassa hyphae in the standard Fries' medium also required $\mathrm{Ca}^{2+}$, but this medium proved unsuitable for detailed studies.

\section{Intracellular distribution of $\mathrm{Ca}^{2+}$}

Since current models often propose a role for $\mathrm{Ca}^{2+}$ gradients in polarized growth, we examined the spatial distribution of $\mathrm{Ca}^{2+}$ in $N$. crassa hyphae. Attempts to measure the 

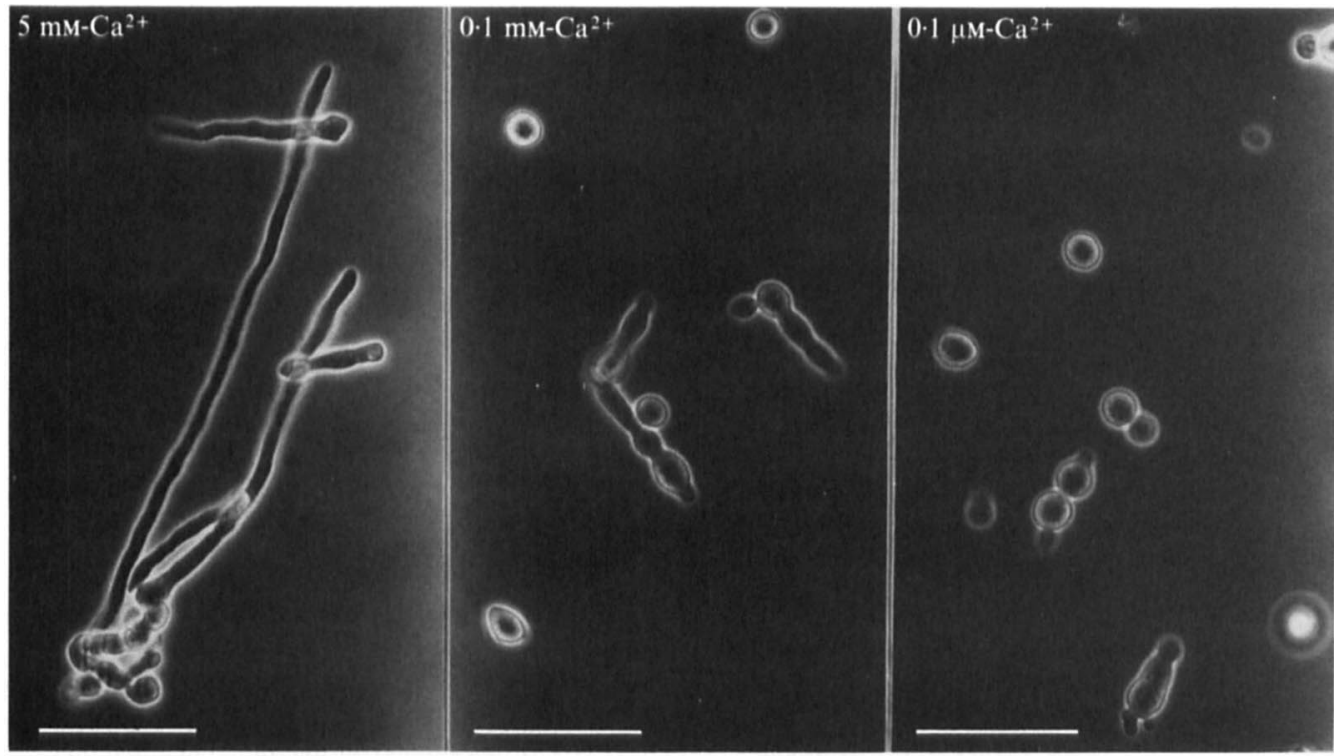

Fig. 2. Morphology of $N$. crassa grown at various $\mathrm{Ca}^{2+}$ concentrations. Growth conditions as for Fig. 1 ; photomicrographs taken after $19 \mathrm{~h}$ of growth. Bars, $50 \mu \mathrm{m}$.

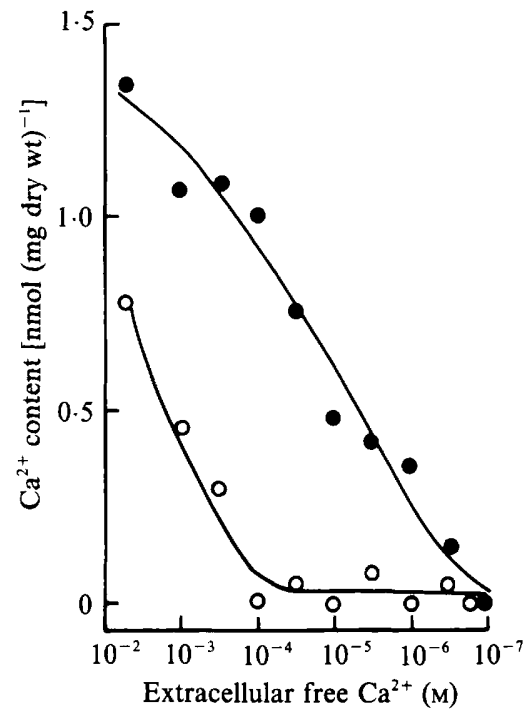

Fig. 3. $\mathrm{Ca}^{2+}$ content of hyphae grown at various concentrations of extracellular ${ }^{45} \mathrm{Ca}^{2+}$. Conditions as in Fig. 1. Intracellular $(O)$ and surface-bound $(O)$ calcium were measured as described in Methods. One of two essentially identical experiments.

distribution of free $\mathrm{Ca}^{2+}$ by the use of fura-2/AM, indo-1/AM or quin-2/AM all failed, because the esterified dyes were either excluded or else not cleaved. We therefore used CTC, which forms a fluorescent complex with $\mathrm{Ca}^{2+}$. The fluorescence intensity increases further when the complex binds to membranes. Since $\mathrm{Ca}^{2+}$ ions in the complex are in equilibrium with those of the cytosol, CTC fluorescence gives some indication of the spatial distribution of total intracellular $\mathrm{Ca}^{2+}$, the bulk of which is bound to membrane surfaces or organelles (Caswell, 1979; Blinks et al., 1982; Kauss, 1987). We observed a clear apical gradient of CTC fluorescence (Fig. 4). The gradient was visible in every one of several hundred growing hyphae we examined; inhibition of growth by cycloheximide or sodium azide led to dissipation of the gradient within $1 \mathrm{~h}$ (data not shown). Young germlings (16-35 $\mu \mathrm{m}$ in length) did not exhibit a clear gradient: the apical region always displayed enhanced fluorescence, but there were also areas of increased 


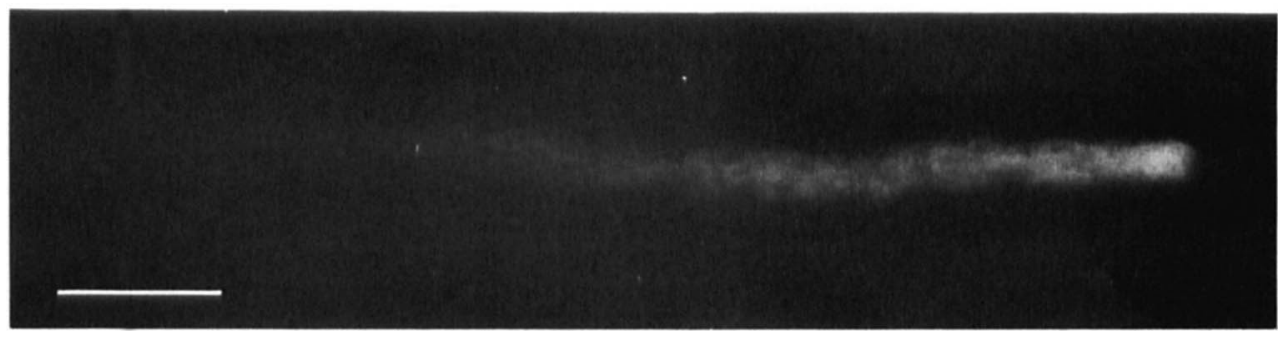

Fig. 4. The gradient of intracellular $\mathrm{Ca}^{2+}$ displayed by CTC fluorescence. Bar, $20 \mu \mathrm{m}$.

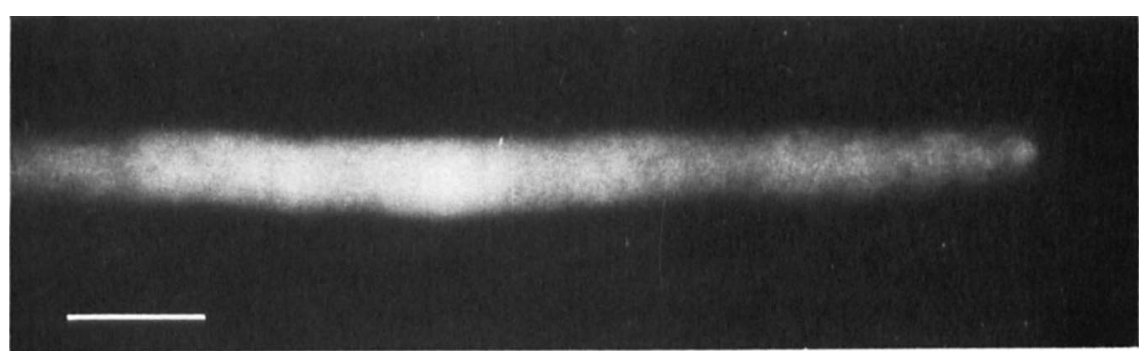

Fig. 5. Distribution of intracellular membranes displayed by NPN fluorescence. Bar, $20 \mu \mathrm{m}$.
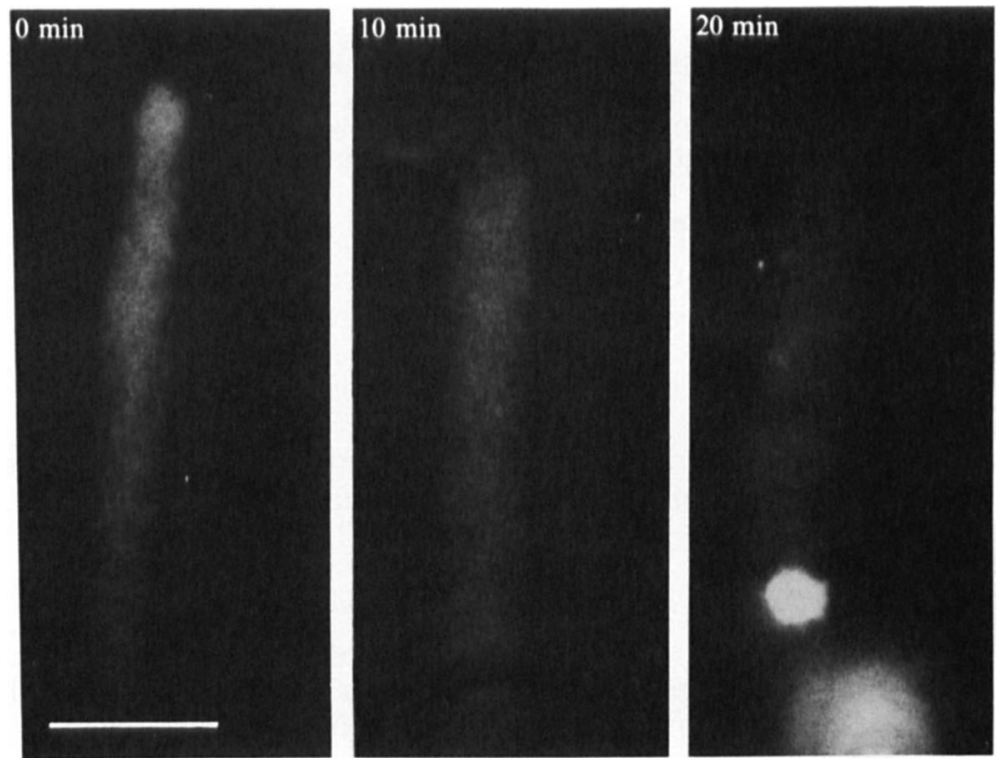

Fig. 6. Effect of the ionophore A23187 on CTC fluorescence. The times after addition of A23187 are indicated on the photomicrographs. The bright spots on the 20 min photomicrograph are caused by A23187 precipitated onto the surface of the hypha. Bar, $20 \mu \mathrm{m}$.

fluorescence behind the apex and in the conidium (data not shown, because we could not obtain satisfactory photomicrographs of germlings).

CTC fluorescence does not depend on $\mathrm{Ca}^{2+}$ alone, but is affected by membrane density and $\mathrm{Mg}^{2+}$ ions as well (Caswell, 1979; Blinks et al., 1982). The distribution of intracellular. membranes was assessed with the fluorescent probe NPN (Ballard et al., 1972). The pattern was variable; only rarely did we observe enhanced apical fluorescence with NPN, and no clear gradient was ever seen (Fig. 5). We can thus exclude the possibility that CTC fluorescence 


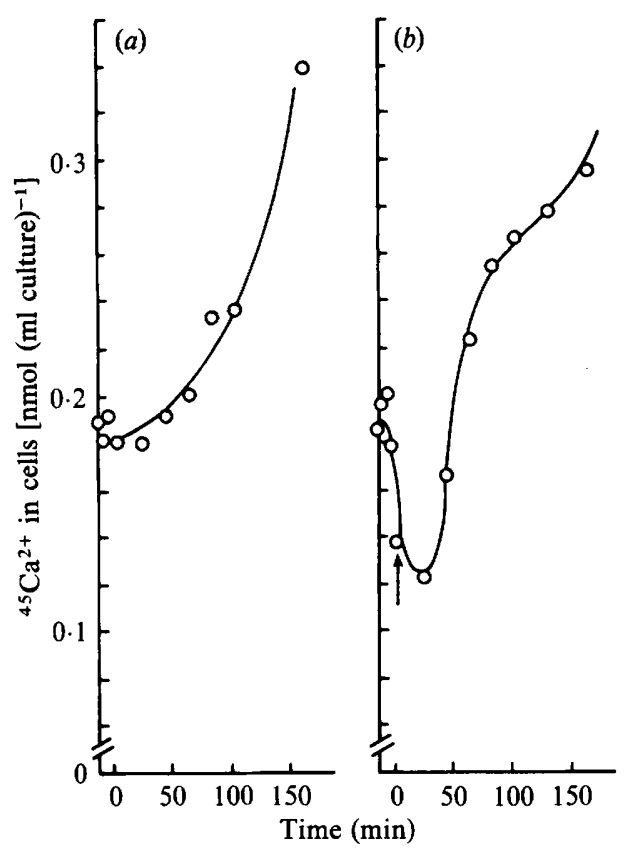

Fig. 7

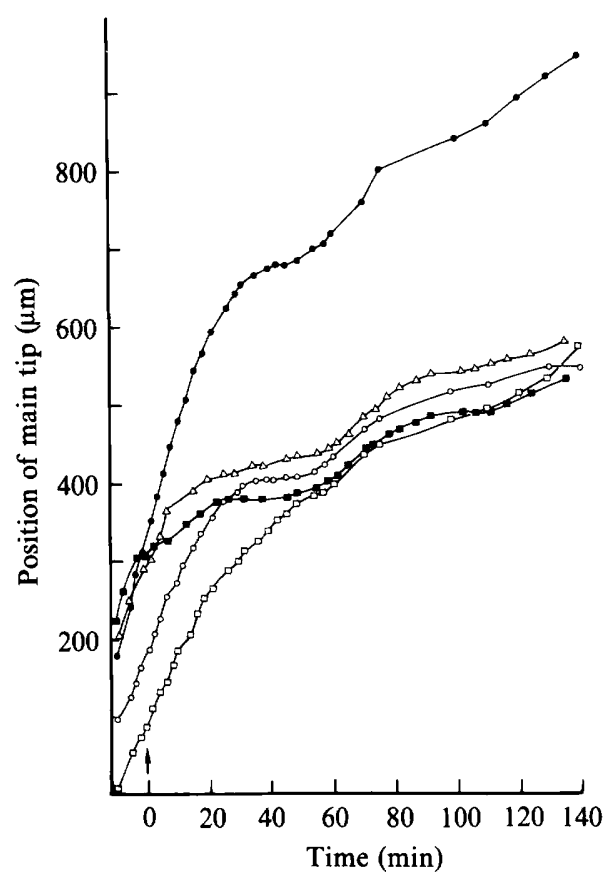

Fig. 8

Fig. 7. Effect of the ionophore $\mathrm{A} 23187$ on the $\mathrm{Ca}^{2+}$ content of $N$. crassa. Hyphae were grown overnight on Fries' medium without added $\mathrm{Ca}^{2+}$ (contamination level, $36 \mu \mathrm{M}$ ), plus ${ }^{45} \mathrm{Ca}^{2+}$. At 0 min the suspension was divided. One half $(a)$ received only dimethylsulphoxide (final concentration $0.2 \%$, the other $(b)$ received A23187 in dimethylsulphoxide (final concentrations $100 \mu \mathrm{M}, 0.2 \%$ ). Samples were collected at intervals thereafter. The rise in ${ }^{45} \mathrm{Ca}^{2+}$ content is due to continued growth of the organisms. This is one of five very similar experiments.

Fig. 8. Effect of the ionophore A23187 on the extension of individual hyphae. $N$. crassa was grown in chambers as described in Methods; at $0 \mathrm{~min}$, the medium was exchanged for medium supplemented with $100 \mu \mathrm{M}-\mathrm{A} 23187$.

reports a gradient of membrane distribution, but some contribution from $\mathrm{Mg}^{2+}$ cannot be ruled out. We shall proceed on the premise that CTC displays the distribution of $\mathrm{Ca}^{2+}$, chiefly that sequestered in organelles.

\section{Does extension require an undisturbed intracellular distribution of $\mathrm{Ca}^{2+}$ ?}

If hyphal extension required a cytoplasmic gradient of free $\mathrm{Ca}^{2+}$, the process should be vulnerable to perturbation of that gradient. A number of $\mathrm{Ca}^{2+}$ antagonists, namely $\mathrm{La}^{3+}(40 \mu \mathrm{M})$, $\mathrm{Gd}^{3+}(40 \mu \mathrm{M})$, Nifedipine $(100 \mu \mathrm{M})$ and Verapamil $(100 \mu \mathrm{M})$, had little or no effect on extension rates or on tip shape; however, they also did not perturb the gradient of CTC fluorescence, nor did they inhibit ${ }^{45} \mathrm{Ca}^{2+}$ uptake.

The effects of the calcium ionophore A23187 $(100 \mu \mathrm{M})$ were more remarkable. Upon addition of the ionophore, the CTC fluorescence gradient started to disperse immediately: after $10 \mathrm{~min}$, fluorescence was much reduced and its intensity was but slightly enhanced at the tip; after $20 \mathrm{~min}$, no more than a weak uniform fluorescence remained (Fig. 6). The ionophore also immediately affected the $\mathrm{Ca}^{2+}$ content of the hyphae, reducing it to $25-60 \%$ of its original value within $20 \mathrm{~min}$ (Fig. 7). The latter effect was transitory: within 40-60 min, the hyphae recovered their $\mathrm{Ca}^{2+}$ complement. We are not certain whether the normal pattern of CTC fluorescence was also re-established, because of interference from the blue fluorescence of the ionophore, which was progressively incorporated by the cells in the course of the experiment. The effects of A23187 on hyphal extension and morphology were considerably milder. Extension was only 

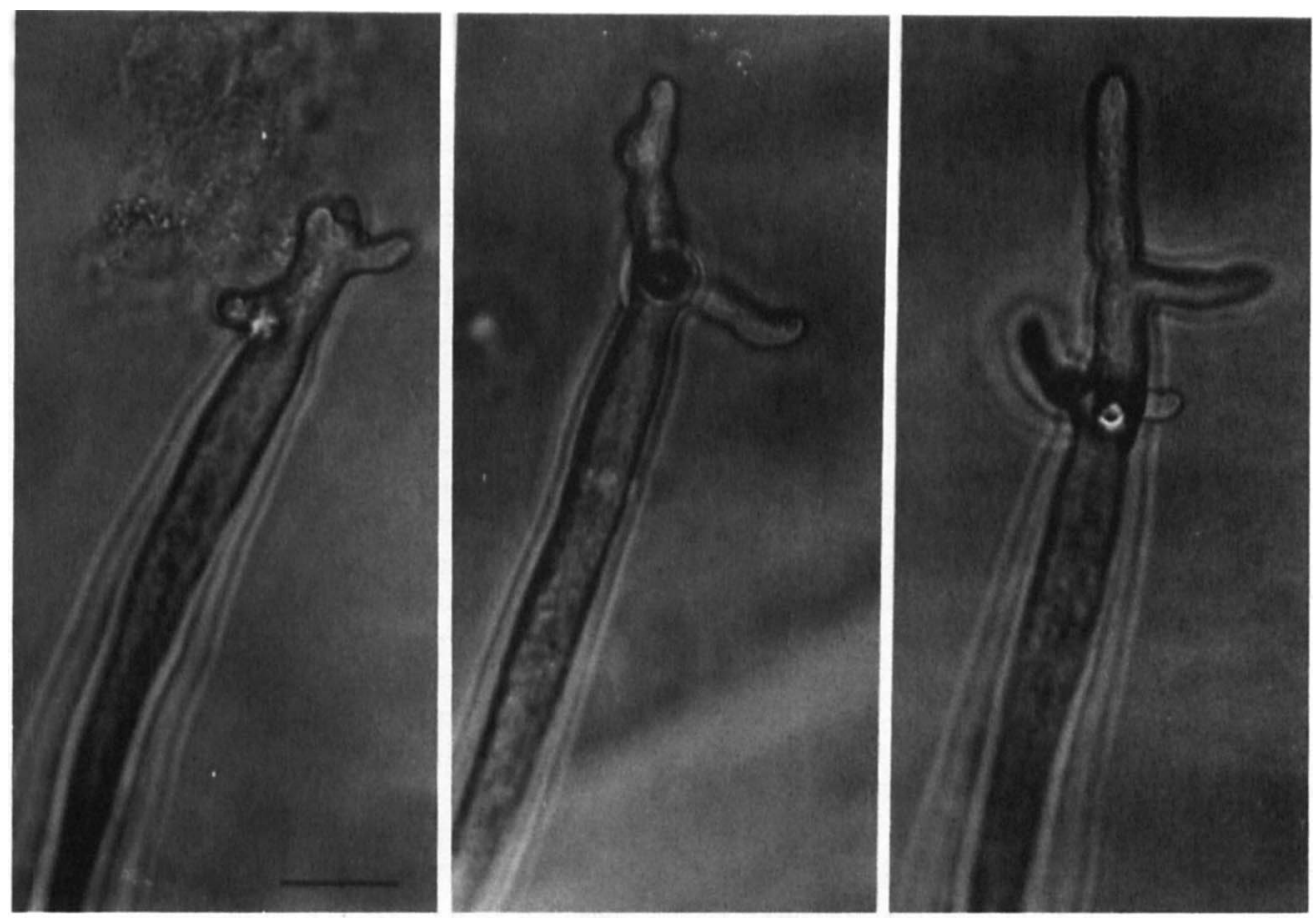

Fig. 9. Effect of the ionophore A23187 on the morphology of the apical region. The hyphae illustrated here were photographed $10 \mathrm{~min}$ after the addition of ionophore under the conditions of Fig. 8. Bar, $20 \mu \mathrm{m}$.

slightly affected for the first $30 \mathrm{~min}$ following addition of the ionophore; it then slowed or even ceased for 20-30 min (Fig. 8). The ionophore also induced the emergence of multiple apical branches, some of which appeared as early as 5 to $10 \mathrm{~min}$ after addition (Fig. 9). Apart from distortion of the original tip during the initial stages of branching, hyphal morphology appeared reasonably normal.

\section{DISCUSSION}

$\mathrm{Ca}^{2+}$ ions are required for the growth of $N$. crassa, but it appears that polarized extension has a higher requirement for $\mathrm{Ca}^{2+}$ than does biomass increase (Fig. 1). In particular, at external concentrations of free $\mathrm{Ca}^{2+}$ below $100 \mu \mathrm{M}$, biomass increase was almost normal but extension was seriously impaired and morphological abnormalities were becoming apparent (Fig. 2). At this level of $\mathrm{Ca}^{2+}$ the 'intracellular' $\mathrm{Ca}^{2+}$ content was still high, whereas the amount of $\mathrm{Ca}^{2+}$ associated with the surface was less than a tenth of that seen at $5 \mathrm{~mm}$ extracellular $\mathrm{Ca}^{2+}$ (Fig. 3). These results suggest that surface-bound $\mathrm{Ca}^{2+}$ ions serve an essential function in generating the normal hyphal morphology. In future, it may be possible to learn whether external $\mathrm{Ca}^{2+}$ ions are mainly needed to ensure the functioning of the cytoplasmic membrane, to confer mechanical strength upon the wall, or are involved in its assembly.

Intracellular $\mathrm{Ca}^{2+}$ ions, in $N$. crassa as in other eukaryotic organisms, probably participate in multiple regulatory functions, some of which require the hyphae to maintain a low level of free cytosolic $\mathrm{Ca}^{2+}$. The recent report that mutants defective in the transport of $\mathrm{Ca}^{2+}$ into a vacuolar fraction are subject to inhibition by extracellular $\mathrm{Ca}^{2+}$ (Cornelius \& Nakashima, 1987) supports this presumption. It seems likely, then, that CTC fluorescence mainly reports the distribution of membrane-bound compartments that sequester the bulk of the $\mathrm{Ca}^{2+}$ complement of the hyphae. The morphology of the CTC-bright bodies is quite unlike that of the large, spherical vacuoles; they may correspond to endoplasmic reticulum (Carafoli, 1987). 
Judging by CTC fluorescence, sequestered $\mathrm{Ca}^{2+}$ in $N$. crass $a$ is distributed along a pronounced gradient, maximum apically (Fig. 4). We were unable to investigate the distribution of free $\mathrm{Ca}^{2+}$, but by extrapolation from recent work with pollen tubes and Fucus (Nobiling \& Reiss, 1987; Brownlee \& Wood, 1986) we would expect that to exhibit a similar distribution. The question is whether such gradients play a causal role in polarized extension, and the effects of A23187 supply a hint. The ionophore elicited an immediate loss of $\mathrm{Ca}^{2+}$ from the hyphae, apparent both as a decline in the ${ }^{45} \mathrm{Ca}^{2+}$ content and as the loss of CTC fluorescence. The loss of $\mathrm{Ca}^{2+}$ occurred despite the presence of $900 \mu \mathrm{M}-\mathrm{Ca}^{2+}$ in the medium. It is not clear just what the ionophore does; one possibility is that it affects the permeability of the calcium storage organelles more severely than that of the plasma membrane, so that the hyphae manage to maintain a relatively normal level of free cytosolic $\mathrm{Ca}^{2+}$.

$\mathrm{Be}$ this as it may, the dissipation of the CTC fluorescence and the massive calcium fluxes observed with ${ }^{45} \mathrm{Ca}^{2+}$ suggest a significant perturbation of intracellular $\mathrm{Ca}^{2+}$ gradients. The disturbance probably extends to the spatial distribution of free cytosolic $\mathrm{Ca}^{2+}$, though we have no direct evidence of that. Despite this perturbation of $\mathrm{Ca}^{2+}$ gradients, the hyphae continued to extend in a polarized manner and their appearance was approximately normal. In fact, during the first 20 min following ionophore addition, the majority of the hyphae continued to extend at the normal rate. The effects of A23187 are far from being understood and must be regarded with some suspicion. Nevertheless, the lack of immediate and severe inhibition of extension by A23187 argues against the hypothesis that a spatial gradient of $\mathrm{Ca}^{2+}$ guides apical extension. The major morphological consequence of A23187 addition was the rapid appearance of apical branches (Fig. 9). A simple and exceedingly tentative interpretation is that $\mathrm{Ca}^{2+}$ gradients are not required to polarize extension, but may be involved in assuring the predominance of a single tip.

J.S. was supported by a research fellowship from the Deutsche Forschungsgemeinschaft. This work was supported in part by Public Health Service grant AI-03568 from the National Institute of Allergy and Infectious Diseases.

\section{REFERENCES}

Ballard, S. G., Barker, R. W., Barrett Bee, K. J., DWeK, R. A., RadDa, G. K., Smith, D. S. \& TAYLOR, J. A. (1972). The location and response of probes in membranes. In Biochemistry and Biophysics of Mitochondrial Membranes, pp. 257-275. Edited by G. F. Azzone, E. Carafoli, A. L. Lehninger, E. Quagliariello \& N. Siliprandi. New York: Academic Press.

Blinks, J. R., Gil Wier, W., Hess, P. \& PrenderGAST, F. G. (1982). Measurement of $\mathrm{Ca}^{2+}$ concentrations in living cells. Progress in Biophysics and Molecular Biology 40, 1-114.

BRADFORD, M. M. (1976). A rapid and sensitive method for the quantitation of microgram quantities of protein utilizing the principle of protein-dye binding. Analytical Biochemistry 72, 248-254.

BROWNLEE, C. \& WOOD, J. W. (1986). A gradient of cytoplasmic free calcium in growing rhizoid cells of Fucus serratus. Nature, London 320, 624-626.

Caldwell, J. H., Van Brunt, J. \& Harold, F. M. (1986). Calcium-dependent anion channel in the water mold Blastocladiella emersonii. Journal of Membrane Biology 89, 85-97.

Caldwell, P. C. (1970). Calcium chelation and buffers. In Calcium and Cellular Function, pp. 10-16. Edited by A. W. Cuthbert. New York: St Martins Press.

CARAFOLI, E. (1987). Intracellular calcium homeostasis. Annual Review of Biochemistry 56, 395-433.
Caswell, A. H. (1979). Methods of measuring intracellular calcium. International Review of Cytology 56, 145-181.

CoRnelius, G. \& NAKASHIMA, H. (1987). Vacuoles play a decisive role in calcium homeostasis in Neurospora crassa. Journal of General Microbiology 133, 23412347.

DAVIES, R. H. \& DE SERRES, F. J. (1970). Genetic and microbiological research techniques for Neurospora crassa. Methods in Enzymology 17A, 79-145.

Dawson, R. M. C., Elliott, D. C., ElliotT, W. H. \& JONES, K. M. (1986). Data for Biochemical Research. Oxford: Clarendon Press.

Dow, J. M. \& Rubery, P. H. (1975). Hyphal tip bursting in Mucor rouxii: antagonistic effects of calcium ions and acid. Journal of General Microbiology 91, 425-428.

HAROLD, R. L. \& HARold, F. M. (1986). Ionophores and cytochalasins modulate branching in Achlya bisexualis. Journal of General Microbiology 132, 213219.

HePleR, P. K. \& Wayne, R. O. (1985). Calcium and plant development. Annual Review of Plant Physio$\log y$ 36, 397-439.

JAFFe, L. A., WeISENSEel, M. H. \& JAFFe, L. F. (1975a). Calcium accumulation within the growing tips of pollen tubes. Journal of Cell Biology 67, 488492.

JafFe, L. F., Robinson, K. R. \& Nuccitelli, R. 
$(1975 b)$. Calcium currents and gradients as a localizing mechanism. In Developmental Biology, pp. 135-147. Edited by D. McMahon \& C. F. Fox. Menlo Park: W. A. Benjamin.

KAUSS, H. (1987). Some aspects of calcium-dependent regulation in plant metabolism. Annual Review of Plant Physiology 38, 47-72.

KROPF, D. L. \& QuATRANo, R. S. (1987). Localization of membrane-associated calcium during development of fucoid algae using chlortetracycline. Planta 171, 158-170.

Labarca, C. \& Paigen, K. (1980). A simple, rapid and sensitive DNA assay procedure. Analytical Biochemistry 102, 344-352.

Ohya, Y., MiYamoto, S., Ohsumi, Y. \& AnRaku, Y. (1986). Calcium-sensitive cls4 mutant of Saccharomyces cerevisiae with a defect in bud formation. Journal of Bacteriology 165, 28-33.

Nobiling, R. \& ReIss, H.-D. (1987). Quantitative analysis of calcium gradients and activity in growing pollen tubes of Lilium longiflorum. Protoplasma 139, 20-24.

Picton, J. M. \& SteER, M. W. (1982). A model for the mechanism of tip extension in pollen tubes. Journal of Theoretical Biology 98, 15-20.

Picton, J. M. \& STEeR, M. W. (1983). Evidence for the role of $\mathrm{Ca}^{2+}$ ions in tip extension in pollen tubes. Protoplasma 115, 11-17.

Picton, J. M. \& Steer, M. W. (1985). The effects of ruthenium red, lanthanum, fluorescein isothiocyanate and trifluoperazine on vesicle transport, vesicle fusion and tip extension in pollen tubes. Planta 163 , 20-26.

Pitt, D. \& Ugalde, U. O. (1984). Calcium in fungi. Plant, Cell and Environment 7, 467-475.
ReISS, H.-D. \& HeRTH, W. 1978). Visualization of the $\mathrm{Ca}^{2+}$-gradient in growing pollen tubes of Lilium longiflorum with chlortetracycline fluorescence. Protoplasma 97, 373-377.

ReISs, H.-D. \& HeRTH, W. (1979). Calcium gradients in tip growing plant cells visualized by chlortetracycline fluorescence. Planta 146, 615-621.

REISS, H.-D. \& HERTH, W. (1985). Nifedipine-sensitive calcium channels are involved in polar growth of lily pollen tubes. Journal of Cell Science 76, 247-254.

REISS, H.-D., GRIME, G. W., LI, M. Q., TAKACS, J. \& WATT, F. (1985). Distribution of elements in the lily pollen tube tip, determined with the Oxford scanning proton microprobe. Protoplasma 126, 147-152.

Reissig, J. L. \& KinNeY, S. G. (1983). Calcium as a branching signal in Neurospora crassa. Journal of Bacteriology 154, 1397-1402.

RoBINSON, K. R. \& JAFFe, L. F. (1975). Polarizing fucoid eggs drive a calcium current through themselves. Science 187, 70-72.

SCHNEPF, E. (1986). Cellular polarity. Annual Review of Plant Physiology 37, 23-47.

SILVER, S. (1977). Calcium transport in microorganisms. In Microorganisms and Minerals, pp. 49-102. Edited by E. D. Weinberger. New York: Marcel Dekker.

SLAYMan, C. L. (1965). Electrical properties of Neurospora crassa. Effects of external cations on the intracellular potential. Journal of General Physiology 49, 69-92.

Van Brunt, J., Caldwell, J. H. \& Harold, F. M. (1982). Circulation of potassium across the plasma membrane of Blastocladiella emersonii: $\mathrm{K}^{+}$channel. Journal of Bacteriology 150, 1449-1461. 